Competing Interests: None declared.

Ethical approval: Not applicable.

Author's contribution: $N N^{\prime}$ and $M H^{2}$ prepared the manuscript in entirety.

\section{Funding:}

None declared.

Acknowledgements: NN likes to acknowledge Prof. John Domingue for providing feedback on the paper and Kris Selezinka for his contributions to the paper

\title{
Medical Education on the Blockchain
}

Naseem Naqvi ${ }^{1}$, Mureed Hussain ${ }^{2}$

${ }^{1}$ Royal College of Physicians of Edinburgh \& The British Blockchain Association, UK

${ }^{2}$ Society for Acute Medicine, UK

Correspondence: naseem@britishblockchainassociation.org

Received: 5 October 2018 Accepted: 25 October 2018 Published: 15 November 2018

\section{Abstract}

The traditional medical education ecosystems* are largely centralised and confined to the boundaries of academic institutions [1]. Rather than promoting efficiency and global forward thinking, a number of medical institutions have become inwardly focused, confining themselves to their own institutional rules and frameworks [2,3]. In the past two years, the utility of blockchain in the higher education setting has been extensively studied [4]. A blockchain is essentially a distributed, immutable, trustworthy, decentralised database that keeps an irreversible, time-stamped record of transfer of value between users for every operation that has ever been carried out on its network [5]. This has traditionally been used in cryptocurrency transactions, however, with the rise of blockchain based Decentralised Applications (DApps), the potential benefits of this ground-breaking technology in higher education are now being explored [6]. Although still in the early developmental stages, blockchain holds promising potential for use in medical education. Some of these are budding hypothesis while in other areas, we have witnessed real, tangible progress [7].

This article analyses the potential use cases for blockchain deployment in medical education ecosystems, to improve the efficiency, security, functionality and effectiveness of existing infrastructures [8]. We conclude the essay by proposing how blockchain can eliminate the growing problem of fraudulent academic accreditations.

Keywords: blockchain, medical education, decentralised applications, credentialing, CPD, certification, learning

${ }^{*}$ Medical Education [9] for the sake of this article refers to 9 broad categories of educational ecosystem (both 'oneoff' events such as credentialing, assessments and verifications, and 'lifelong' learning, such as CPD) applicable to Undergraduate Medical Students, Postgraduate Doctors, Nurses \& Allied Disciplines including Paramedic staff: $a$. Identity and learner records management; $b$. Funding, payment and educational e-commerce; $c$. Medical MetaUniversity - 'Medical Education without borders'; $d$. Global medical assessment; e. Validation, Authentication, and Certification; $f$. Learner credentialing; g. Clinical E-learning; h. Medical CPD (Continued Professional Development); i. Learning in clinical settings \& clinical apprenticeships.

\section{Historical Overview of Medical Education Ecosystems}

Medical Education ecosystems can be categorized into i. 9 key domains:

a. Identity and learner records management

b. Funding, payment, and educational e-commerce

c. Medical Meta-University - 'Medical Education without borders'

d. Global medical assessment

e. Validation, Authentication, and Certification

f. Learner credentialing g. Clinical E-learning

h. Medical CPD (Continued Professional Development) Learning in clinical settings \& clinical apprenticeships

\section{What is Medical Education?}

\section{Definitions}

Wikipedia defines Medical Education as 'education related to the practice of being a medical practitioner; either the initial training to become a physician (i.e., medical school and internship), or additional training thereafter (e.g., residency and fellowship).' 


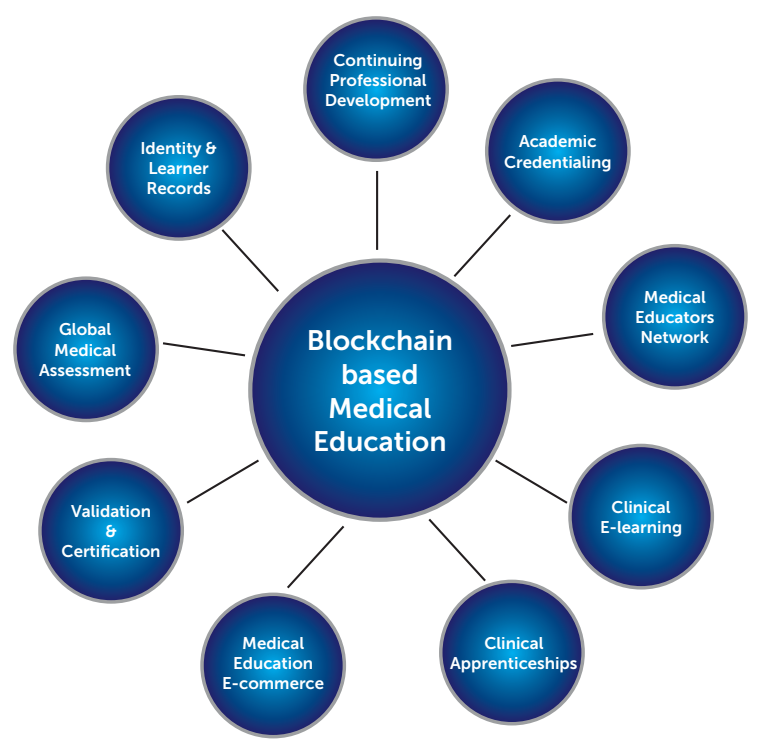

Brittanica defines Medical Education as "course of study directed toward imparting to persons seeking to become physicians the knowledge and skills required for the prevention and treatment of disease. It also develops the methods and objectives appropriate to the study of the still unknown factors that produce disease or favour well-being. Among the goals of medical education is the production of physicians sensitive to the health needs of their country, capable of ministering to those needs and aware of the necessity of continuing their own education.

\section{Utility of Blockchain in Medical Education}

\section{Identity, Leaner Records \& Credentialing}

Organisations spend significant amount of time and resources on verification of academic credentials $[10,11,12,13]$. By awarding theses credentials on a blockchain, an immutable, independently verifiable and time stamped record can be permanently stored [14]. In case of lost records (asylum/refugee medical students/doctors with no access to their primary institution) or a doctor/medical student transferring to other institutions, a transcript on the blockchain is instantly available and globally accessible without the need to request a duplicate copy from the awarding institution [15]. The data is cryptographically encrypted, so only those who have the digital keys can access the credentials.

Use case:

A doctor from Syria receives his medical diploma on a blockchain. He owns and controls the "private keys" to his blockechain account. He moves to the UK after becoming a refugee. The Medical Council in the UK is unable to contact his parent institution. Since the 'hash' - the unique digital stamp of his degree is issued on a blockchain, the transcript is independently verifiable. He later applies for registration with the General Medical Council which was able to independently verify bis credentials without having the need to consult the original institution.

\section{Blockchain based learning \& CPD}

Medical education is rapidly evolving and is becoming increasingly multidisciplinary. Medical students and doctors are increasingly required to collect a broad range of CPD incorporating both clinical and nonclinical activities [16]. The blockchain can collect realtime evidence of learning, which can be stored and shared instantly with the relevant bodies [17]. It will also make it time and resource effective to monitor attendance records, releasing CPD certificates on the blockchain and capturing synchronous learner feedback. Furthermore, this is of incredible value in reaffirmation of learner's ownership of academic records and the CPD [18].

Use case:

A CPD event organiser registers all participants on the blockechain. The access to the entire programme of activities is available on the blockchain. Participants scan the "QR code" of each presentation at the time of registering their attendance. Through a decentralised mobile app (DApps), real-time feedback is submitted both to the presenter and organiser's accounts.

Since the certificate of participation is also issued to the attendees on a blockechain, there are

significant cost and time savings both to the participants and the organisers. The CPD "reflection" is recorded on the blockechain which can be connected with the learner's portfolio in real-time.

\section{Medical Education without borders - Blockchain based Medical Education Network}

Learning in a clinical environment is increasingly complex and can be difficult to record [19]. It is often a real challenge to chart out of programme and selfdirected learning [20]. Medical students and doctors learn vast amounts of knowledge and skills that are difficult to reflect, verify, acknowledge and validate [21]. Frequently, it is almost impossible to track the learning back to every single source. Since the validation on blockchain takes place at the time of creation of a record and not afterwards, a blockchain based program could offer a solution to this challenging dilemma. It is now practically possible for educational content to be encrypted, validated, time stamped and made available on a blockchain [22]. Educational content is immutably stored on a decentralised ledger [23]. The learner is able to access the data from anywhere in the world and give instant feedback to the creator by "hash tagging" the relevant bits of information. This will then be credited to the creator's portfolio in a completely decentralised, permanent, tamper proof form of evidence. A system based on blockchain will also acknowledge contribution to the society in general which would otherwise have not been possible - a system of education that takes the activity out of the traditional realms of institutions to a completely global, universally accessible ecosystem. 


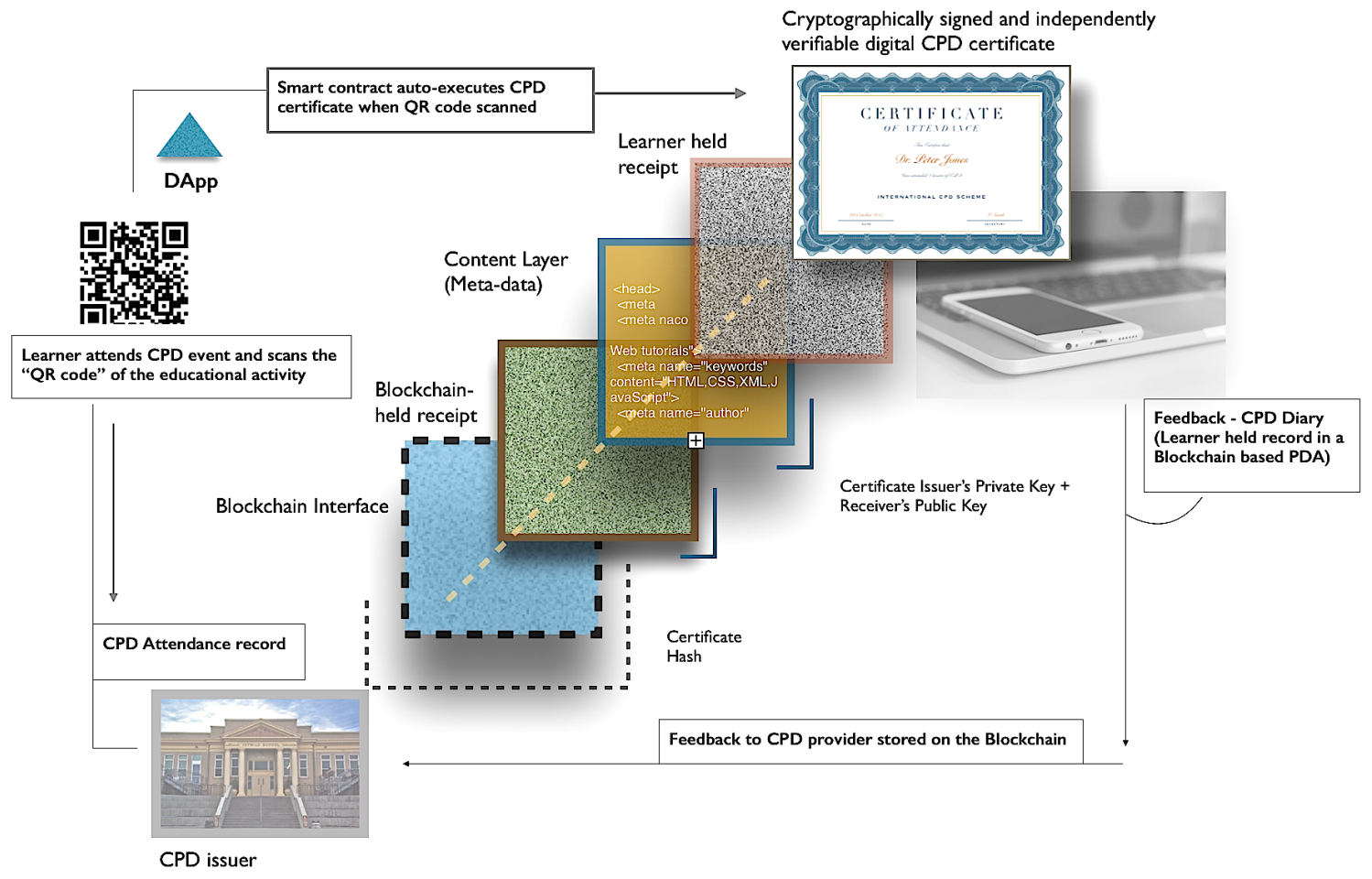

(Source: Copyrights Naqvi, N 2018, The British Blockchain Association)

IDEALISTIC SOLUTION DESIGN - A 360 degree complete CPD Loop

Technology stack: Blockchain based CPD, Certification and Feedback

Cryptography would ensure transparency, visibility and complete user control in a peer-to-peer fashion without the need of a trusted intermediary [24].

Use case:

A medical student goes to Nigeria on a placement where he spends time in the community doing volunteer work. He also spends two weeks in general practice and a week in the laboratory. Since the learning log is accessible on a blockechain based PDA, assessments and reflections can be stored in real-time on a permanent ledger. Assessors can provide contemporaneous feedback which can be digitally stored on the blockchain. The log book of placement can then be shared in a confidential manner with the assessors and university staff. Each entry is time stamped, independently verifiable and permanently recorded on the student's university file.

\section{'Smart Contracts' \& 'Medical Education Hub'}

Medical education "tokens" can be created on a decentralized Blockchain. They can be used to pay for educational services directly from a mobile wallet. This will enable end users to connect directly with the education service providers and allow them to pay for educational services in digital currency.

The digital tokens could also be awarded for academic achievements which can be accepted as a recognition of award by multiple institutions on the basis of a pre-agreed criteria. A blockchain based platform will allow users to search, connect, and pay for educational services in a self-sustaining e-commerce eco-system that will be globally accessible in all countries that permits its operations within their regulatory framework [25]. A digital gateway will allow educational facilities to manage student's information, rewards, and participation in educational activities in a more streamlined way.

Use cases:

Enable institutions to register as Education Service Providers and auto-execute smart contracts based on pre-agreed sets of principles [26]

Advertise academic courses, conferences, publications, projects, books, magazine, journal, research article, seminars, tutorials, lectures, workshops to a global blockchain community

Search for services by category, discipline or tutor and book directly via blockchain payment portal without the need of an intermediary

Incentivize the creators of educational contents in the form of digital tokens or certificates delivered peer-to-peer, without the need of a trusted third party Option to share educational content on social 
media directly from a blockchain portal Options to rate tutors, courses and institutions in real time and share the feedback with multiple stakeholders

Connect and share knowledge with everyone connected to the blockchain eco-system, benefitting from a close-knit, global medical network.

\section{Validation \& Certification}

The explosion of fake degrees and organisations that produce them (dubbed by many as "diploma mills") has created a lot of uncertainty in not only the academic space but also the public's trust of professionals. This growing problem with fake credentials undermines the very fabric of higher learning as it depreciates the time, hard work and underlying value in the pursuit of higher education. Unfortunately, there are grave differences when we are speaking about how people view the legitimacy between the business and medical fields. It is one thing for there to be distrust of the President of Microsoft China [27], but it is much worse if people start to doubt the capabilities of their medical professionals. This can lead to a whole host of concerns such as patients not following instructions regarding drug intake, rehabilitation or many others and then resorting to blame the lack of confidence in the caregiver as the reason for their continuing problems or ailments. Individuals with fake degrees put the public at risk as their stated skill set is lacking due to minimal knowledge or a complete absence of training. Some go so far as to use their phony credentials to earn people's trust and then abuse it to sell self-concocted snake oil on the internet and lure patients from real medication. This is exactly what happened when two men who purchased their doctors' ID's for $\$ 100$ took a young girl off insulin who died after taking their potion [28]. They were subsequently charged with manslaughter in North Carolina.

This problem has existed for centuries but recently exploded in the past few decades due in large part to advances in technology. Perhaps the most famous recent example of widespread abuse involves the Axact company in Pakistan inventing over 300 fake universities and using fabricated news stories to fool employers who might check references. This year Axact's CEO and 22 employees received 20-year sentences each for their fake degree mill [29]. That may seem large, but it pales in comparison as to the recent explosion of this in China in the last ten years. The problem has become so widespread that there are websites being created outing these frauds along with "true or false" portals where users can verify schools not listed. China's ministry of education has been actively targeting crackdowns as well.

It has also been observed where individuals posing as medical professionals are teaching with their "doctored" doctorates [30]. At one of my former alma maters, the University of Victoria, Mr. Jason Matthew Walker taught courses in child and youth care in 2006. This not only undermines the school involved but jeopardizes the legitimacy of the degrees of the students being taught. He later became a manager of residential services at Glengarry Hospital. The spokesperson for the Vancouver Island Health Authority Shannon Marshall stated "We wouldn't routinely check the credentials of any junior of middle manager unless there was some indication they needed to be verified'. Once an individual is caught with illegitimate degrees it is not always an easy process to try and decipher how many of the degrees this person claims to hold are real and how many are simply bought on the internet.

Former FBI agent Allen Ezell claims over half of the $\mathrm{PhDs}$ issued in the United States every year are fake [30] and details this phenomenon extensively in the book he co-wrote Degree Mills: The Billion Dollar Industry that has sold over a million fake diplomas. The fake diploma market dates back as far as the 14th century in Europe [31] and of the estimated 200,000 fake diplomas per year issued by mills based in the United States alone, a sizeable portion is estimated to be "awarded" to those in the medical field. Using the various blockchain methods detailed above, we believe this could be the answer to a centuries old problem that is becoming much more pervasive with time. The amount of labour, energy and money expended by individuals trying to combat this growing problem could be saved by creating open and transparent blockchain academic certificates that genuinely reflect the true work expended by the student.

\section{Conclusion}

Medical Education is rapidly evolving and blockchain could play a central role in the creation, organization, management, and delivery of educational systems. Medical education could immensely benefit from adoption of blockchain technology. It can create a smart bionetwork based on a cutting-edge technology and has the potential to cause a paradigm shift in the academic space. It is setting foundations for a transformational breakthrough in medical education. Although the balance of a new technology set being implemented in a world of established ideas can present itself as a conceptual challenge, a close collaboration with academic institutions and the learner community could help blockchain technology become an integral part of medical education infrastructures in the foreseeable future. We are incredibly optimistic about the use of blockchain architectures in digitized Medical Education systems.

\section{References}

1. Neame, Roderick et al. "Universities without Walls: Evolving 
Paradigms in Medical Education." BMJ: British Medical Journal 319.7220 (1999): 1296. Print.

https:/ / www.ncbi.nlm.nih.gov/pmc/articles/PMC1129074/

2. Athol, K: "Medical Schools without walls." Medical Education (2009)

bttps:// doi.org/10.1111/j.1365-2923.1997.tb02558.x

3. Hou Jianlin et al. "Transformation of the education of health professionals in China: progress and challenges. The LANCET (2014) bttps://wnw.sciencedirect.com/science/article/pii/ S0140673614613076

4. JRC Publications Repository - Europa EU 'Blockechain in Education”. (2017) bttp://publications.jrc.ec.europa.eu/ repository/bitstream/JRC108255/jrc108255_block.chain_ in_education $\% 281 \% 29$.pdf

5. Wikipedia: "What is a Blockechain":

bttps:/ / en.wikipedia.org/ wiki/Blockechain

6. Peters, A: "Can blockchain disrupt health, education, licensing \& credentialing?"

The LANCET (2017)

http:/ /globalhealth.thelancet.com/2017/10/31/canblockchain-disrupt-health-education-licensing-and-credentialling

7. CoinDesk: US Medical Board Group Launches Blockchain Certification" (2017) (bttps:/ / www.coindesk.com/us-medicalboard-group-launches-blockechain-certification-pilot)

8. Schunirth, Lambert WT, and Cees P M van der Vleuten. "Medical education: Challenges for educationalists:" BMJ: British Medical Journal 333.7567 (2006): 544-546. PMC. Web. 1 Apr. 2018.

bttps:/ / wmw.ncbi.nlm.nih.gov/pmc/articles/PMC1562480/ 9. Wikipedia - What is Medical Education: https:// en.wikipedia.org/wiki/Medical_education

10. Blockchain for Physician Credentialing: Intel Health \& Life Sciences: (2017) https:// simplecore.intel.com/itpeernetwork/ wp-content/ uploads/sites/38/2017/05/Intel_Blockchain_ Application_Note2.pdf

11. Blockechain Technology \& Healthcare Credentialing: An Introduction (April 2017)

bttp:/ / wnw.namss.org/Portals/0/Regulatory/NAMSS\%20 Blockechain\%20Introduction.pdf

12. Distributed Ledger Technologies for Public Good: (2017) http:/ / chrisholmes.co.uk/wp-content/ uploads/2017/11/ Distributed-Ledger-Technologies-for-Public-Good_leadershipcollaboration-and-innovation.pdf

13. How much money do businesses spend annually on background checks? (2017)

https: / / www.quora.com/How-much-money-do-businessesspend-annually-on-background-checks

14. Sony wants to digitize education records using the blockechain: (2017) bttps:// techcrunch.com/2017/08/09/sony-educationblockechain

15. Providing Pathways for Refugees: Practical Tips for Credential Assessment: (2016)

https: / / wenr.wes.org/2016/04/providing-pathways-forrefugees-practical-tips-for-credential-assessment

16. Continuing Professional Development - A guidance for all doctors:

https:/ / www.gmc-uk.org/Continuing_professional_ development___guidance_for_all_doctors_0316. pdf_56438625.pdf
17. 10 things to know about the future of Blockchain in Education: https:// wnw.edtechstrategies.com/blog/futureblockechain-education/

18. Blockchain and Education: A Big Idea in need of bigger thinking: https:/ / wnw.coindesk.com/ blockchain-education-bigidea-need-bigger-thinking/

19. Teaching and Learning in Clinical Settings, Volume 425; 2006:

https:/ / books.google.co.uk/ books?isbn $=1857757513$

20. The challenge of self-directed and self-regulated learning in vocational education: A theoretical analysis and synthesis of requirements:

https:/ / wmw.researchgate.net/publication/228875710_The_ challenge_of_self-directed_and_self_regulated_learning_in_ vocational_education_A_theoretical_analysis_and_synthesis_ of_requirements

21. We lived and breathed medicine - then life catches up: Medical students' reflections:

bttps:/ / wnw.ncbi.nlm.nih.gov/pmc/articles/PMC4230426/ 22. How Can Blockechain Technology Innovate Your Education: https:/ / hackernoon.com/ how-can-blockchain-technologyinnovate-your-education-d1 cd80c26f08

23. Morshed, J: What Blockechain could mean for Higher Education: https:// edtechnology.co.uk/Article/whatblockechain-could-mean-for-higher-ed

24. Blockchain in research and education | Jisc:

https:/ / www.jisc.ac.uk/ / reports/blockchain-in-research-andeducation

25. What Happens When You Combine Blockechain and Education?

https:/ / hackernoon.com/what-happens-when-you-combineblockechain-and-education-d533ef6d4862

26. The Blockechain for Education; An introduction:

bttp:/ / hackeducation.com/2016/04 / 07 / blockechaineducation-guide

27. How blockechain can stamp out fake diplomas: 2017

https:/ / www.forbes.com/sites/lamsharon/2017/10/08/

how-blockchain-can-stamp-out-chinas-fakediplomas/\#6cc5a6636854

28. Your MD may have a phony degree 2017

bttps: / / www.cbsnews.com/ news/your-md-may-have-a-phonydegree/

29. Axact CEO, 22 others receive 20 years in jail for fake degrees case: 2018 https:// wmw.dawn.com/ news/1418156 30. How easy is it to fake it as a doctor? 2017 https:/ / wmw.bbc.com/news/ uk-40861475

31. B.C. doctor accused of fake credentials 2010 https:/ / wnw. theglobeandmail.com/news/british-columbia/bc-doctor-accusedof-fake-credentials/ article4301066/ 